\title{
Comparative In Vitro Cytotoxicity of 20 Potential Food Ingredients in Canine Liver, Kidney, Bone Marrow-Derived Mesenchymal Stem Cells, and Enterocyte-like Cells
}

\author{
Nancy A. Monteiro-Riviere, Maria T. Ortega, Kyoungju Choi, Juraj Koci,, \\ Zhoumeng Lin, Brett Jeffery, ${ }^{2}$ and Jim E. Riviere ${ }^{1}$
}

\begin{abstract}
To begin development of a mechanistically relevant humane alternative platform for safety assessment of dog food ingredients, comparative in vitro cytotoxicity of 20 ingredients was assessed in four canine cell types relevant for toxicity assessments. Previously, we described the toxicity of 13 compounds (clove leaf oil, eugenol, guanosine monophosphate [GMP], GMP plus inosine monophosphate, sorbose, ginger root extract, cinnamon bark oil, cinnamaldehyde, thyme oil, thymol, lemon grass oil, xylitol, and citric acid) using in vitro primary canine cell culture models for liver, kidney, bone marrow-derived mesenchymal stem cells (BMSC), and enterocyte-like cells (ELC). In this report, dose-response cytotoxicity studies and $\mathrm{LC}_{50}$ using alamar blue assays are reported for seven additional compounds: denatonium benzoate, eucalyptol, hexahydroisohumulone, tetrahydroisohumulone, green tea catechin extract, epigallocatechin gallate, and sodium copper chlorophyllin. Data across 20 compounds were compared between different cell types and responses were not parallel, precluding the use of a single cell line for in vitro ingredient hazard assessment. Hepatocytes were most resistant to all compounds, consistent with their xenobiotic detoxification functions. BMSC and ELC showed an increase in sensitivity to the essential oils eucalyptol, eugenol, and thymol compared to renal cells and hepatocytes. These studies provide a baseline of acute cytotoxicity of 4 canine cell types to 20 different food components that begin to illustrate how such an in vitro panel could be used for hazard assessment.
\end{abstract}

Key words: bone marrow stem cells, canine, enterocytes, food ingredients, in vitro, kidney, liver

\section{Introduction}

$\mathbf{T}$ HE ASSESSMENT OF THE SAFETY of chemical ingredients in pet foods can be an overwhelming task, especially if such studies must be conducted in target animal species. A recent National Research Council (NRC) ${ }^{1}$ study explored how the safety of dietary substances should be assessed in horses, dogs, and cats. ${ }^{1}$ A common misconception is that products widely found in human food (e.g., garlic and chocolate) are assumed to be safe for pets. In contrast, the major conclusion of the NRC report was that safety in humans or any one species does not guarantee safety in another. This parallels the situation in human toxicity testing where animal studies often are not predictive of human adverse events. ${ }^{2}$ The NRC report documents the lack of in vivo toxicology studies in companion animals, which leads to difficulty in making safety assessments of dietary supplements in these species. A safety assessment of natural products often relies on the documented history of safe food use without any additional animal toxicity or human clinical data. ${ }^{3}$ The NRC report suggested that evaluation of the safety of animal dietary supplements using in vitro studies is valuable in describing the potential for toxic effects, mechanisms of action, and biological plausibility of adverse signals seen after in vivo exposure. ${ }^{1}$ Such studies serve as a bridge to similar in vitro cytotoxicity evaluations conducted in other laboratory species or humans. This strategy

\footnotetext{
${ }^{1}$ Department of Anatomy and Physiology, College of Veterinary Medicine, Kansas State University, Manhattan, Kansas.

${ }^{2}$ Mars Global Food Safety Center, Yanqi Economic Development Zone, Huairou, Beijing, P.R. China.

(c) Nancy A. Monteiro-Riviere et al. 2015; Published by Mary Ann Liebert, Inc. This Open Access article is distributed under the terms of the Creative Commons License (http://creativecommons.org/licenses/by/4.0), which permits unrestricted use, distribution, and reproduction in any medium, provided the original work is properly credited.
} 
is also consistent with the philosophy espoused by the Toxicity Testing in the 21st Century paradigm, where in vitro studies are a key link to define the mechanism of action of study chemicals-a prerequisite for making more integrated safety assessments in other species. ${ }^{2,4}$ The process of assessing the safety of pet food ingredients is complex and in vitro studies alone are not sufficient. As with most other areas of toxicology, but especially prevalent for animals widely owned as pets, there is pressure for developing alternative methods to humanely assess the safety of pet food products. Such alternative in vitro screening methods are consistent with the methods to reduce, refine, and replace animal testing with in vitro alternative approaches that are scientifically sound and provide solid signals for selecting pet food ingredients that are safe to target species. In vitro methods are the most obvious choice, especially when multiple target-organ cell lines are selected to produce an integrated panel that uses a range of cells possessing different physiological functions.

Assessment of in vivo safety cannot be accomplished alone using in vitro cell-based assays because the pharmacokinetic processes involving absorption and metabolism are not accounted for, integrated systemic toxicological responses are not detected, immunological hypersensitivity responses cannot be easily determined, and the effects seen after chronic exposure are not amenable to study. Therefore, in vitro studies are useful to assess if unique chemical- and species-specific toxicological responses occur and provide some assessment of organ-specific responses. In vitro studies provide a basis for comparing cytotoxicity data across species when only in vitro data are available. They can be used to predict in vivo toxicity only if independent exposure and pharmacokinetic disposition and metabolism studies are also available. ${ }^{1,5}$

In an effort to begin development of an alternative platform for safety assessment of dog food ingredients, we developed an in vitro canine cell culture for liver, ${ }^{6}$ kidney, ${ }^{7}$ bone marrow-derived mesenchymal stem cells (BMSC), and enterocyte-like cells (ELC). ${ }^{8}$ These primary cells were selected because they represent major excretory and target organs for any systemically absorbed chemical (liver and kidney) and, in the case of enterocytes, are the initial cell type encountered by food ingredients in the gastrointestinal tract, making them the proximate target cell for direct contact with food ingredients. Use of this diverse cell panel thus provides a range of different cells with widely different biological functions (transporters, metabolizing enzymes, etc.) to assess potential adverse effects after chemical exposure. Initial published studies involved optimization of harvest and cell culture conditions. Cytotoxicity was expressed, using the alamar blue viability assay, as the lethal concentration of the test substance that killed $50 \%$ of exposed cells $\left(\mathrm{LC}_{50}\right)$. Thirteen compounds were initially assessed: clove leaf oil (CLO), eugenol (EUG), guanosine monophosphate (GMP), GMP plus inosine monophosphate (IMP), sorbose (SORB), ginger root extract (GRE), cinnamon bark oil (CBO), cinnamaldehyde (CINA), thyme oil (TO), thymol (THYM), lemon grass oil (LGO), xylitol (XYL), and citric acid (CA). These data, along with studies validating specific positive cellular toxicity markers and other mechanistic endpoints, were published previously for the canine liver, ${ }^{6}$ kidney, ${ }^{7}$ BMSC, and ELC. ${ }^{8}$
The research described herein, and in previous work, represents the first steps to building such an integrated system focused on the dog. The present study used these previously described cell culture systems and assessed the cytotoxicity of seven additional compounds: denatonium benzoate (DB), eucalyptol (EUC), hexahydroisohumulone (HEX), tetrahydroisohumulone (TRA), green tea catechin extract (GTE), epigallocatechin gallate (EPI), and sodium copper chlorophillin (SCC). The previous articles should be consulted for more specific details on the background of the original ingredients tested. ${ }^{6-8}$

DB is a bittering agent used to enhance bitter flavor, as an aversive additive in household products to discourage consumption of poisonous substances, and also in cosmetics as a denaturant. The human bitterness threshold is $0.05 \mathrm{ppm}$ for the benzoate form of denatonium. ${ }^{9}$ DB has been used to discourage consumption of rat poison, ethylene glycol, and methanol-containing products such as antifreeze and wiper fluids. In mice and rats, the $\mathrm{LD}_{50}$ was $865 \mathrm{mg} / \mathrm{kg}^{9}$ and $485-740 \mathrm{mg} / \mathrm{kg},{ }^{10}$ respectively. The G protein-coupled bitter taste receptors (TAS2R) respond to DB stimulation, ${ }^{11}$ triggering both metabolic and immunologic responses. DB $(10 \mu \mathrm{M})$ can promote fat and protein digestion through the stimulation of cholecystokinin secretion in enteroendocrine cells $^{12}$ and in stimulating innate immunity as it activates T2R-mediated antimicrobial peptide secretion in primary human sinonasal epithelial cells. ${ }^{13}$

EUC (1,8-cineole) is naturally found in thyme (58\%), cardamom $(73 \%)$, cranberry (15\%), laurel, rosemary, marjoram citric fruit peel oils, and ginger. ${ }^{14-16}$ EUC is used as a flavoring agent in baked goods, meat products, and beverages. ${ }^{15}$ EUC has antimicrobial activity at $\mathrm{IC}_{50} 35-62 \mu \mathrm{g} / \mathrm{ml}$ and is not toxic to mouse macrophages or bovine aortic endothelial cells. ${ }^{16} \mathrm{At}$ an $\mathrm{IC}_{50}$ of $80-94 \mu \mathrm{g} / \mathrm{ml}$, EUC inhibits HSV-2 in RC-37 cells $\left(\mathrm{IC}_{50} 0.3 \mathrm{mg} / \mathrm{ml}\right)$ and infectious bronchitis virus hosted in Vero cells $\left(\mathrm{IC}_{50} 10 \mathrm{mg} / \mathrm{ml}\right) .{ }^{17,18}$ It exerts analgesic and antiinflammatory activity ${ }^{19,20}$ and inhibits proinflammatory cytokines in lymphocytes and monocytes. ${ }^{21}$ EUC is considered weakly genotoxic, causing oxidative DNA damage (771 ng/ $\mathrm{ml}$ ) in cells. ${ }^{22}$ A dose of $381 \mathrm{mg} / \mathrm{kg}$ of EUC showed subacute renal toxicity in rats based on the accumulation of the eosinophilic protein droplets in the proximal tubule cell cytoplasm. ${ }^{23}$

Humulus lupulus L. (Cannabaceae), commonly known as hops, is a preserving and bittering ingredient in the brewing industry as well as used for medicinal purposes. ${ }^{24}$ Hops $\alpha$ acids (humulone) and $\beta$-acids (lupulones) constitute the essential bitter resin. Boiling of hops $\alpha$-acid, humulone, causes isomerization; further hydrogenation yields TRA, with borohydride treatment yielding HEX. ${ }^{25,26}$ These reduced isohumulones were fed to rats for 90 days and did not cause adverse effects at $150 \mathrm{mg} / \mathrm{kg}$. TRA at $50 \mathrm{mg} / \mathrm{kg}$ and HEX at $100 \mathrm{mg} / \mathrm{kg}$ fed to dogs for 90 days showed an increase in serum alkaline phosphatase levels that were not attributed to liver toxicity and therefore considered not to cause adverse effects in dogs. ${ }^{26}$ C57BL/6N mice fed a diet with $1 \%$ isohumulone showed hepatomegaly accompanied by reduced plasma triglyceride levels. ${ }^{27}$ Isohumulones also possess anti-inflammatory and anticancer activities. ${ }^{28}$ They can inhibit LPS-induced iNOS activity in RAW 264.7 macrophages at $6-18 \mu \mathrm{g} / \mathrm{ml}$ and induce $\mathrm{NAD}(\mathrm{P}) \mathrm{H}$ :quinone reductase activity at $1-10 \mu \mathrm{g} / \mathrm{ml}$ in murine hepatoma cells with cytotoxicity seen at an $\mathrm{LD}_{50}>20 \mu \mathrm{g} / \mathrm{ml} .^{29}$ 
Green tea derived from Camelis sinensis consists of $30 \%$ polyphenols termed catechins. ${ }^{30}$ The major catechins are (-) epigallocatechin-3-gallate (EPI), (-) epicathin-3-gallate, $(-)$ epigallocatechin, and $(-)$ epicatechin. EPI accounts for $50-80 \%$ of catechins, representing $200-300 \mathrm{mg}$ in a brewed cup of green tea. ${ }^{31}$ Catechins from green tea have been purported to possess many health benefits, including prevention and/or control of cancer, diabetes, kidney/liver injury, vascular diseases, obesity, ${ }^{32,33}$ and oxidative stress, ${ }^{34,35}$ as well as antibacterial and antiviral properties. ${ }^{36,37}$ However, there are case reports regarding human hepatic failure associated with GTE in Europe. ${ }^{38-42}$ High concentration of GTE showed pathological changes and mortality in laboratory animals. ${ }^{43-47}$ High doses of GTE and EPI ( $>1000 \mathrm{mg} / \mathrm{kg})$ caused hepatotoxicity in mice. $^{48}$

Unlike some of the other compounds studied, in vivo catechin studies were reported in dogs. A study showed that $1000 \mathrm{mg}$ purified GTE/ $\mathrm{kg}$ caused a decrease in body weight and reduced food consumption and death starting at day 9 in a 9-month chronic study in beagle dogs. Subsequently, this study was terminated on day 17 because of morbidity and mortality. A follow-up study for 13 weeks of $200 \mathrm{mg} / \mathrm{kg}$ of GTE in fasted dogs resulted in gastrointestinal distress and greater toxicity than dogs in a fed state. ${ }^{45}$ In another 13week study in dogs dosed with 50, 150, and $500 \mathrm{mg}$ GTE/ $\mathrm{kg} /$ day, the NOAEL in dogs for the fasted state was estimated as $50 \mathrm{mg} / \mathrm{kg} .{ }^{45}$ Finally, a NOAEL in prefed beagle dogs and in a fasted state were 500 and $40 \mathrm{mg} \mathrm{EPI} / \mathrm{kg} /$ day, respectively. $^{44}$

SCC is water-soluble sodium copper salt derived from chlorophyll widely used at $0.2 \%$ as an additive for controlling odor and imparting color to dry beverage mixes. ${ }^{49}$ SCC binds to DNA-intercalating mutagenic compounds, potentially preventing chemically induced mutagenesis and carcinogenesis. ${ }^{50} \mathrm{SCC}$ is a potent antioxidant and effective in scavenging reactive oxygen species. In human peripheral blood lymphocytes, SCC at $0.1-100 \mu \mathrm{g} / \mathrm{ml}$ did not decrease cell viability. ${ }^{51}$ SCC at 10 and $100 \mu \mathrm{g} / \mathrm{ml}$ protected cell and DNA damage induced by mycotoxins, ochratoxin $\mathrm{A}$ at $4 \mu \mathrm{M}$, and fumonisin $\mathrm{B}_{1}$ at $20 \mu \mathrm{g} / \mathrm{ml}^{51}$ Additionally, SCC injected into the abdominal wall at $40 \mathrm{mg} / \mathrm{kg} / \mathrm{day}$ for 5 days in mice reverted titanium dioxide nanoparticle $(500$, 1000 , or $2000 \mathrm{mg} / \mathrm{kg} /$ day)-induced DNA damage in hepatocytes $^{52}$ and in mice cardiac cells. ${ }^{53}$ SSC also demonstrated antioxidant activity by an increase in glutathione levels, hepatic superoxide dismutase, catalase, and glutathione peroxidase activities. ${ }^{52} \mathrm{SSC}$ at $4 \mathrm{mg} / \mathrm{kg}$ reduced TGF- $\beta$ signaling, blocked cell proliferation, angiogenesis, invasion, and metastasis, and induced mitochondria-mediated cell death, inhibiting the development of $n$-methyl- $n$-nitro- $n$-nitrosoguanidineinduced forestomach carcinomas. ${ }^{54}$ In aplastic anemic mice fed 25,50 , or $100 \mathrm{mg} / \mathrm{kg} /$ day of SCC, mesenchymal stem cell proliferation, osteo differentiation, and immunomodulation were promoted. ${ }^{55}$

The aims of this article are to report on the cytotoxicity of these additional compounds across four canine cell systems, to compare chemical ingredient response from all studies conducted to date to begin compiling a multicellular canine in vitro cytotoxicity database, to determine the necessity of conducting such analyses in multiple in vitro cell systems, and to assess if specific compounds exhibited unique responses in specific organ cell types.

\section{Materials and Methods}

\section{Chemicals}

Lemon grass oil East-Indian type (LGO) CAS 8007-02-1, ginger root extract (GRE) CAS 84696-15-1, and CLO CAS 8000-34-8 were purchased from Spectrum Chemical (Gardena, CA). Guanosine 5'-monophosphate disodium salt hydrate (GMP) CAS 5550-12-9, inosine 5'-monophosphate disodium salt hydrate (IMP) CAS 352195-40-5, cinnamon bark oil (CBO) CAS 8015-91-6, cinnamaldehyde (CINA) CAS 104-55-2, thyme oil (TO) CAS 8007-46-3, thymol (THYM) CAS 89-83-8, citric acid (CA) CAS 77-92-9, eugenol (EUG) CAS 97-53-0, L-sorbose (SORB) CAS 87-79-6, xylitol (XYL) CAS 87-89-0, GTE Cat \#G-016, EPI CAS 989-51-5, DB CAS 3734-33-6, sodium copper chlorophyllin (SCC) CAS 11006-34-1, and EUC CAS 470-82-6 were purchased from Sigma Aldrich (St. Louis, MO). TRA CAS 28815-20-5 and HEX CAS 685110-34-3 were donated by Kalsec, Inc. (Kalamazoo, MI).

\section{Animals}

The dogs used in these studies were male and female mongrel dogs of indeterminate breed ranging from 1 to 9 years of age ( $n=6 /$ liver, 6/kidney, and 6/BMSC and ELC), averaging $26 \mathrm{~kg}$. Dogs were housed individually under normal environmental conditions at $20-23^{\circ} \mathrm{C}, 40-60 \%$ relative humidity, and $12 \mathrm{hr}$ light/12 hr dark cycle, and provided with food and water ad libitum. All dogs were anesthetized with a 1:1 mixture of ketamine and xylazine (i.v., $55-74 \mu \mathrm{l} / \mathrm{kg}$ ) and within $10 \mathrm{~min}$ euthanized with sodium pentobarbital (i.v., $222 \mu \mathrm{l} / \mathrm{kg}$ ) after owner consent. Dogs were not bred specifically for this research. The use of these tissues for research purposes was approved by the University's Institutional Animal Care and Use Committee Protocol 3214.

\section{Cell culture methods}

The methods used to harvest and culture the cells have been described in great detail in the previous publications for canine primary renal proximal tubule cells of the kidney, ${ }^{7}$ canine hepatocytes for the liver, ${ }^{6}$ and BMSC and ELC differentiation. ${ }^{8}$ For all systems, cells were seeded on 96-well plates and test chemicals dosed at concentrations limited by specific chemical solubility in medium ( $n=3$ for hepatocytes and $n=6$ for proximal tubule cells, BMSC, and ELC wells/concentration) for $24 \mathrm{hr}$. Cell passaging ranged from 9 to 12 for BMSC and ELC, and 4-5 for proximal tubule cells, and hepatocytes were isolated and used directly for these experiments. The alamar blue (aB) viability assay (Invitrogen, Carlsbad, CA) was used to assess the cytotoxicity of all ingredients. Cell viability was assessed by adding a 1:10 dilution of the $\mathrm{aB}$ reagent to the cell culture medium followed by $3 \mathrm{hr}$ of incubation. Fluorescence was detected using a synergy $\mathrm{H} 1$ hybrid multimode microplate reader at Ex555/Em585nm (BioTek Instruments Inc., Winooski, VT). Cell viability, which is proportional to an increase in fluorescent intensity, was normalized to controls and expressed as percent viability at $\mathrm{mg} / \mathrm{ml}$ of the test compound.

\section{Data analysis}

$\mathrm{LC}_{50}$ was determined using statistical regression in OriginPro 8 SRP software (OrigeLab Corp., Northampton, 
MA) with resulting data expressed as mean \pm SD for $n=3$ dogs per compound treatment. In some cases, cell viability was not reduced at the solubility-limited highest concentration tested, which precluded determination of an $\mathrm{LC}_{50}$. In these cases, data are denoted as nonlethal (NL) and were not included in the radial compass or 3D plots. Radial compass plots were generated using Microsoft Excel 2010 (Microsoft, Redmond, WA) and 3D plots were generated using SAS 9.3 (SAS Institute Inc., Cary, NC). Correlation coefficients were determined between $\mathrm{LC}_{50}$ of liver (used as point of reference) versus the three cell types for all chemicals with $\mathrm{LC}_{50}$ values using GraphPad Prism 6 (GraphPad Software Inc., La Jolla, CA).

\section{Results}

Dose-response plots and $\mathrm{LC}_{50}$ results for DB, EPI, EUC, GTE, HEX, SCC, and TRA are depicted for canine renal proximal tubule cells (Fig. 1), hepatocytes (Fig. 2), ELC (Fig. 3), and BMSC (Fig. 4). Table 1 is a tabulation of the $\mathrm{LC}_{50}$ for the compounds reported, as well as those previously reported for the canine renal proximal tubule cells, ${ }^{7}$ hepatocytes, ${ }^{6}$ BMSC, and ELC. ${ }^{8}$ Correlation coefficients for regression analyses between the liver (as reference for all compounds for which statistically valid $\mathrm{LC}_{50}$ values could be obtained) and kidney cells, between the liver cells and ELC, and between the liver cells and BMSC were 0.934, 0.991, and 0.990, respectively (all $p<0.0001$ ). This complete data set for all compounds with estimated $\mathrm{LC}_{50}$ and the cell types is graphically compared using a radial compass plot (Fig. 5) and a 3D plot (compound vs. cell type vs. $\mathrm{LC}_{50}$ ) (Fig. 6). In Figures 5 and 6 , compounds are ordered by decrease in toxicity of the hepatocytes as the reference cell type.

Not surprisingly, the toxicity of these very different chemicals has an $\mathrm{LC}_{50}$ ranging from $0.0003 \mathrm{mg} / \mathrm{ml}$ to greater than $400 \mathrm{mg} / \mathrm{ml}$ - a million fold difference. Some compounds are obviously potent in certain cell types, while others are essentially nontoxic. An interesting comparison is the difference between a complete extract versus one of its components, such as GTE vs. EPI or CLO vs. EUG. In the case of green tea, EPI is significantly more toxic than the GTE. In contrast, with clove leaf oil both CLO and EUG are similar. TRA and HEX provide another interesting comparison. As indicated in the Introduction, the $\alpha$-acid humulone HEX is a derivative of TRA. In our studies, there are cell-specific differences in potency across cell lines for TRA/HEX $\mathrm{LC}_{50}$ [ratio]: hepatocytes $0.296 / 0.122$ [2.42], proximal tubule cells $0.016 / 0.037$ [0.43], ELC 0.009/0.023 [0.39], and BMSC 0.031/0.043 [0.72]. Hepatocytes are both less sensitive to TRA (Fig. 1g) and HEX (Fig. 1e) compared to other cell types, and have less sensitivity to TRA [ratio $>1$ ] compared to the other cell types [ratio <1]. Hepatocytes appear to be relatively resistant to SCC (Fig. 2f) compared to the other three cell types. Finally, BMSC are much more sensitive to CA exposure than the other three cell types.

There are a number of interesting trends that can be seen from these data. The first is that the rank order of compound toxicity between different cell types is different, an observation supported by the different correlations (using hepatocytes as the reference cell line) seen in Table 1. The kidney represented by proximal tubule cells is prominent in this regard. The 3D plot (Fig. 6) allows for easy visualiza- tion of the rank order of all compounds across all cell types. In this case, the compounds are ordered by their rank of toxicity in the liver (leftmost pattern), which clearly shows that different order is needed for kidney, ELC, and BMSC. In most cases, hepatocytes are relatively resistant. This suggests that knowing the toxicity in one cell type does not necessarily predict toxicity in another cell type.

The compass plot (Fig. 5) clearly depicts that individual compounds have different responses across all four cell types. These data are again ordered by liver toxicity. Some compounds have very similar responses (e.g., GMP, GRE, TO, and CLO) in all four cell types, while others (e.g., EUC, LGO, CA, and THYM) differ across all cell types or are only different in one cell type (e.g., CA and TRA). THYM, EUG, and EUC show greater toxicity in BMSC and ELC compared to kidney or liver cells.

\section{Discussion}

This work presents the first compilation of comparative toxicity data on a wide variety of chemicals in four different defined primary canine cells that have relevancy for toxicity assessments. ELC represents gastrointestinal-like cells that are in direct contact with food ingredients and would be expected to reflect responses such as acute irritation leading to gastrointestinal distress. Hepatocytes and renal proximal tubule cells represent elimination and biotransformation functions that are responsible for compound elimination and potentially reflective of in vivo liver or kidney toxicity. BMSC are relatively nonspecialized young differentiating stem cells that express ABC transporters ${ }^{56}$ but do not have the full complement of cellular functions associated with fully differentiated cell types, such as expression of intestinal alkaline phosphatase ${ }^{57}$ and fructose transporters. ${ }^{58}$ Our previous study ${ }^{8}$ should be consulted for a full description of the differences between these cell types.

The first observation is that responses between different cell types do not parallel one another, thereby precluding the use of a single cell line for in vitro assessment of ingredient hazards. However, there are some general patterns that can be noted. Proximal tubule cells have the weakest correlation to hepatocytes (Table 1), a finding potentially consistent with the numerous transmembrane transport systems present in these excretory cells, which the other cell types do not possess. Hepatocytes tended to be more resistant to all compounds studied, a finding consistent with their xenobiotic detoxification functions. An interesting finding was the unique response of hepatocytes to the hop-derived humulones, HEX (Fig. 2e), and its hydrogenated precursor TRA (Fig. 2g). Hepatocytes were relatively resistant and showed an inverse ratio of sensitivities to TRA versus its reduction product HEX, compared to all cell types. This suggests a unique hepatic response to these hop-derived humulones that would not be predicted from studying the other cell types, again most probably secondary to the specialization of hepatocytes for xenobiotic biotransformation. ${ }^{5}$ The most sensitive cell type to these humulones is ELC, especially to TRA, which would be the first cells encountered after oral exposure.

It is not appropriate to conduct detailed comparisons across compounds because chemicals were selected for various reasons, and not to define a balanced and representative 

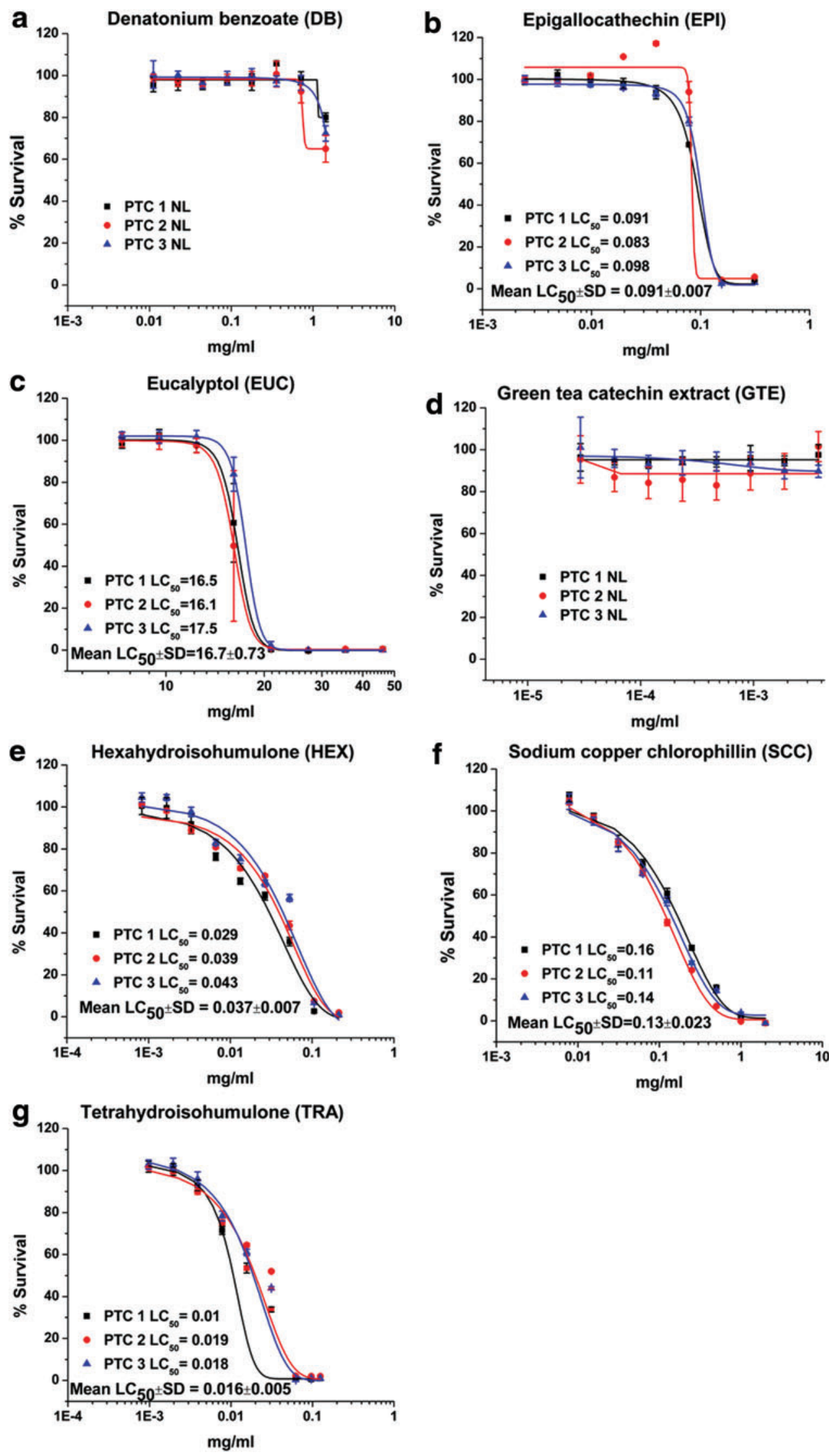

FIG. 1. Viability and $\mathrm{LC}_{50}(\mathrm{mg} / \mathrm{ml})$ for (a) DB, (b) EPI, (c) EUC, (d) GTE, (e) HEX, (f) SCC, and (g) TRA after $24 \mathrm{hr}$ in canine renal PTC determined in three independent cell lines plotted as mean \pm SD of six technical replicates within cell lines. DB, denatonium benzoate; EPI, epigallocatechin gallate; EUC, eucalyptol; GTE, green tea catechin extract; HEX, hexahydroisohumulone; PTC, proximal tubule cells; SCC, sodium copper chlorophillin; TRA, tetrahydroisohumulone. Color images available online at www.liebertpub.com/aivt 

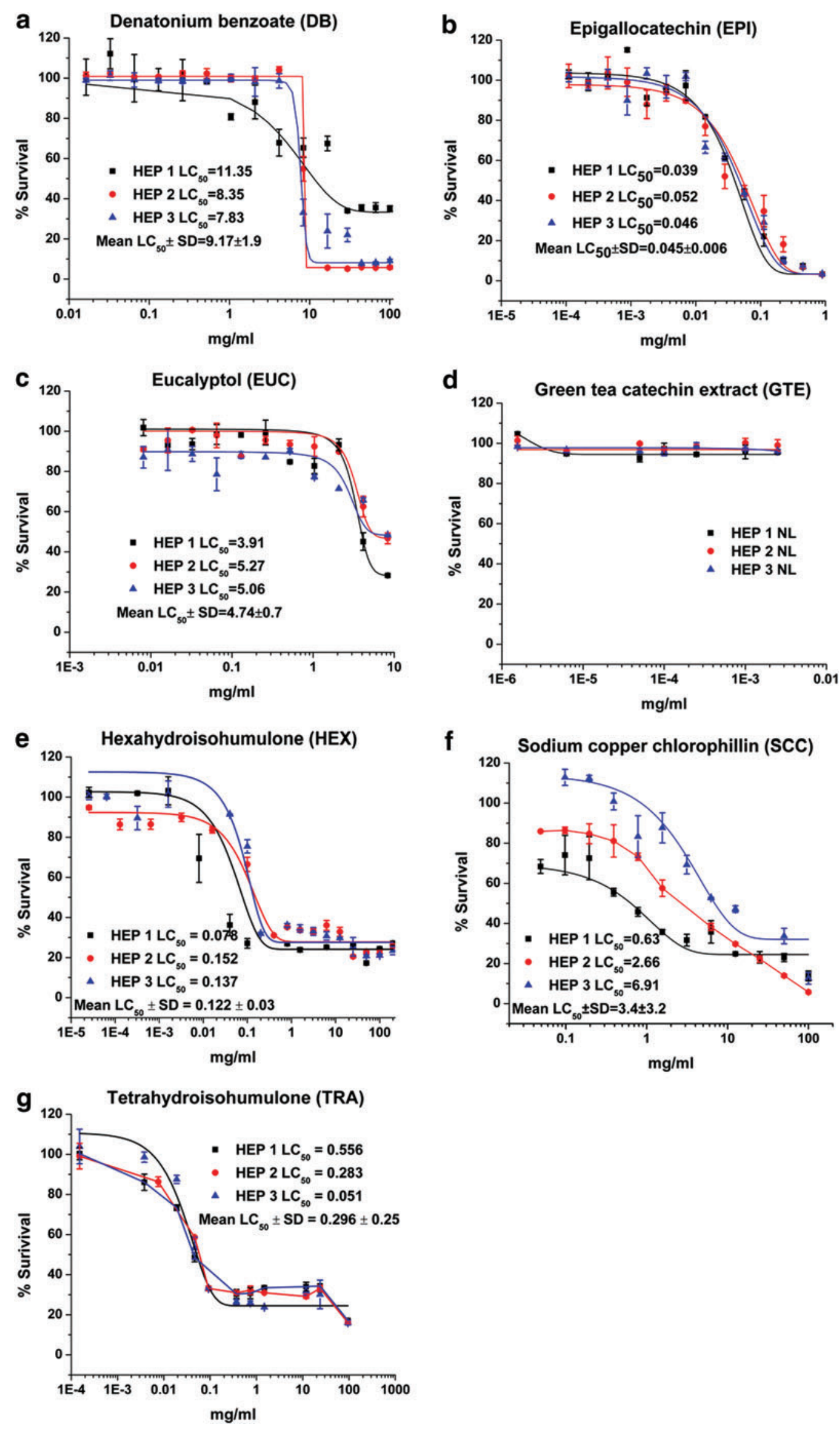

FIG. 2. Viability and $\mathrm{LC}_{50}(\mathrm{mg} / \mathrm{ml})$ for (a) DB, (b) EPI, (c) EUC, (d) GTE, (e) HEX, (f) SCC, and (g) TRA after $24 \mathrm{hr}$ in canine hepatocytes (HEP) determined in three independent cell lines plotted as mean \pm SD of three technical replicates within cell lines. Color images available online at www.liebertpub.com/aivt 

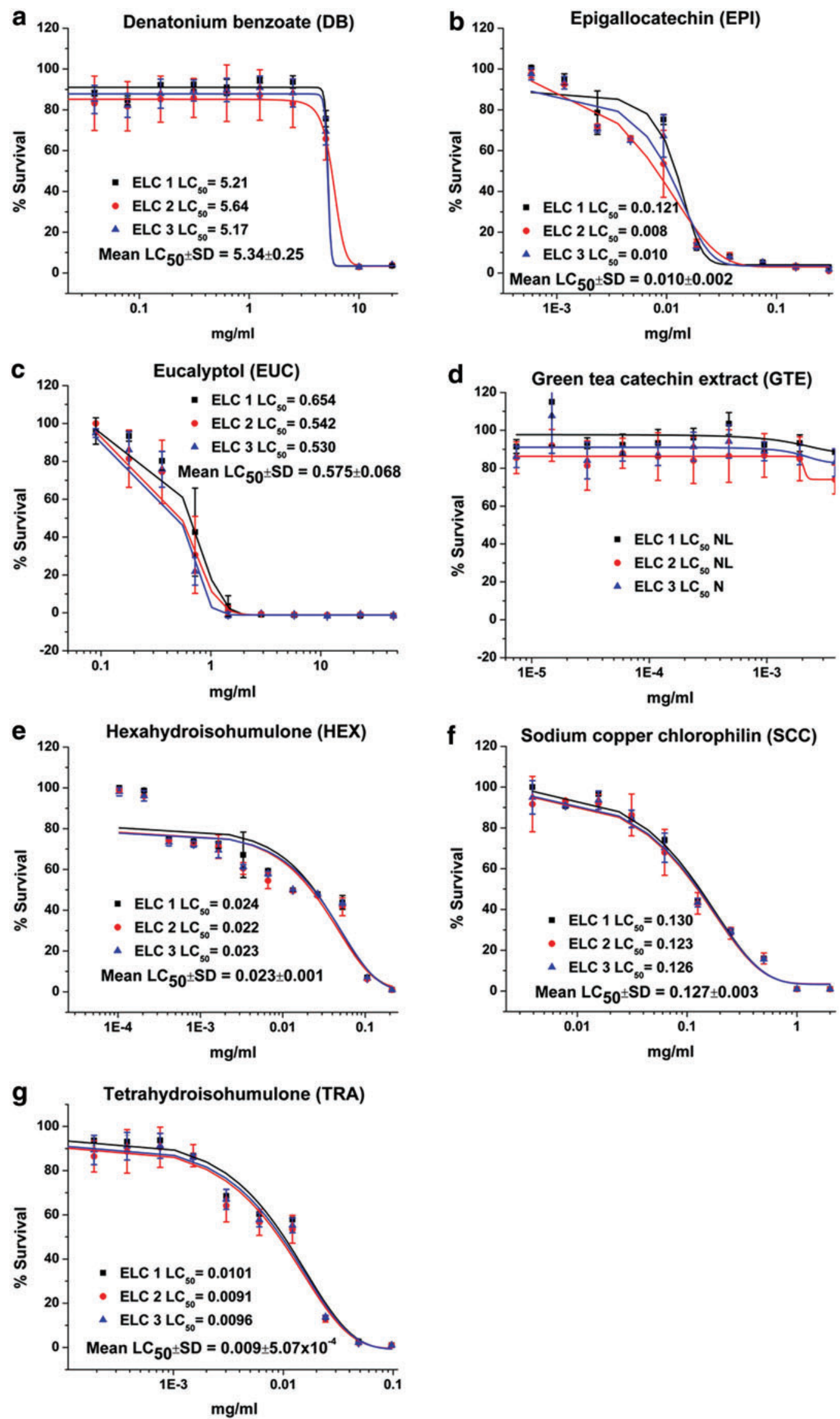

FIG. 3. Viability and $\mathrm{LC}_{50}(\mathrm{mg} / \mathrm{ml})$ for (a) DB, (b) EPI, (c) EUC, (d) GTE, (e) HEX, (f) SCC, and (g) TRA after $24 \mathrm{hr}$ in canine enterocyte-like cells (ELC) determined in three independent cell lines plotted as mean \pm SD of six technical replicates within cell lines. Color images available online at www.liebertpub.com/aivt 

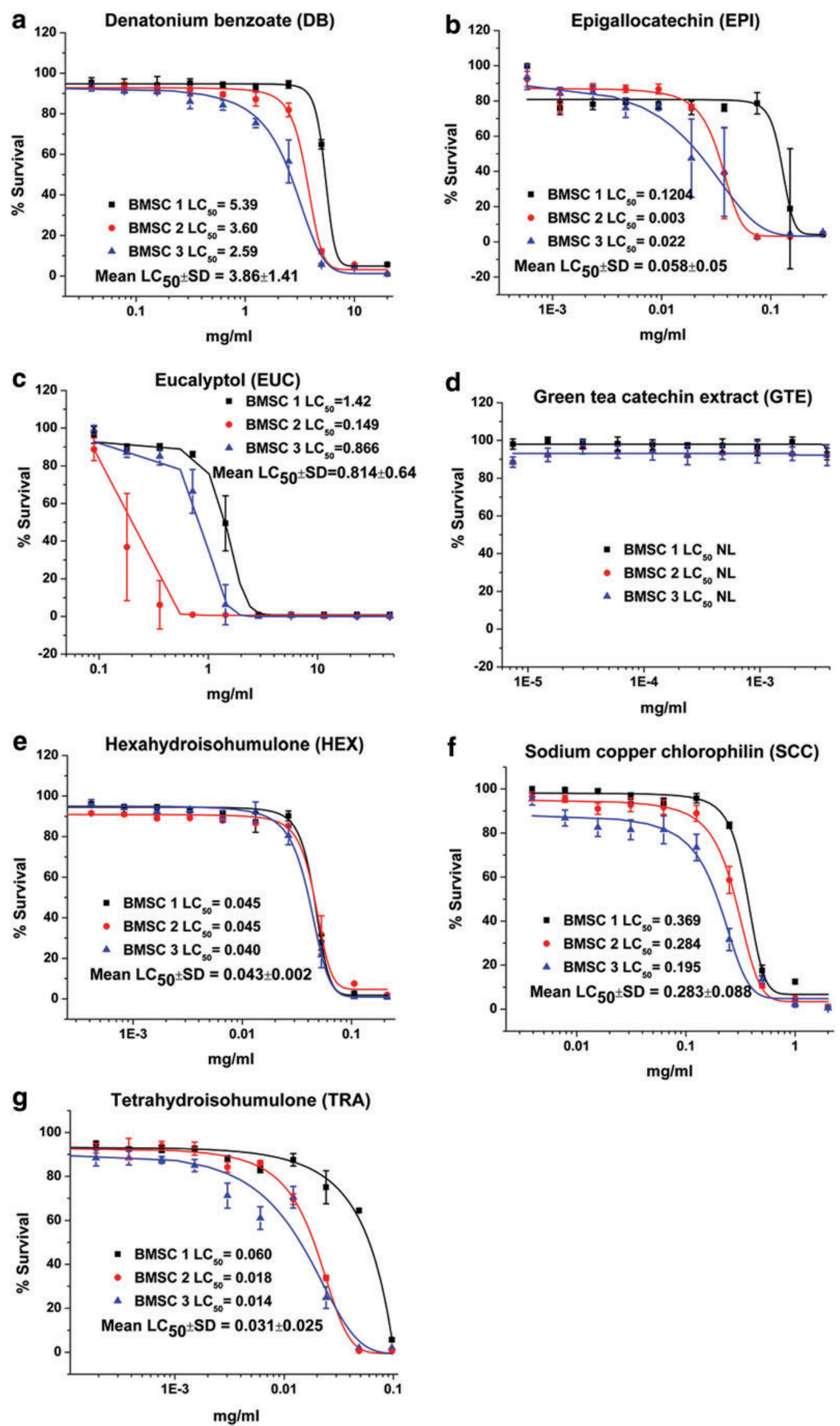

FIG. 4. Viability and $\mathrm{LC}_{50}(\mathrm{mg} / \mathrm{ml})$ for (a) DB, (b) EPI, (c) EUC, (d) GTE, (e) HEX, (f) SCC, and (g) TRA after $24 \mathrm{hr}$ in canine bone marrow-derived stem cells (BMSC) determined in three independent cell lines plotted as mean \pm SD of six technical replicates within cell lines. Color images available online at www.liebertpub.com/aivt 
Table 1. LC $_{50}$ Values of 20 Compounds in IN Vitro Canine Cell Cultures

\begin{tabular}{|c|c|c|c|c|c|}
\hline \multirow[b]{2}{*}{ Compound } & \multirow[b]{2}{*}{ Abbreviation } & \multicolumn{4}{|c|}{$L C_{50} \pm S D(\mathrm{mg} / \mathrm{ml})$} \\
\hline & & Hepatocytes & $\begin{array}{l}\text { Proximal renal } \\
\text { tubule cells }\end{array}$ & $\begin{array}{c}\text { Enterocyte-like } \\
\text { cells }\end{array}$ & $\begin{array}{c}\text { Bone marrow-derived } \\
\text { stem cells }\end{array}$ \\
\hline Cinnamaldehyde & CINA & $0.11 \pm 0.01$ & $0.012 \pm 0.002$ & $0.037 \pm 0.01$ & $0.077 \pm 0.002$ \\
\hline Cinnamon bark oil & $\mathrm{CBO}$ & $0.08 \pm 0.03$ & $0.019 \pm 0.004$ & $0.054 \pm 0.01$ & $0.111 \pm 0.002$ \\
\hline Citric acid & $\mathrm{CA}$ & $1.58 \pm 0.08$ & $1.03 \pm 0.005$ & $1.25 \pm 0.47$ & $0.02 \pm 0.001$ \\
\hline Clove leaf oil & CLO & $0.185 \pm 0.075$ & $0.18 \pm 0.02$ & $0.099 \pm 0.011$ & $0.119 \pm 0.0004$ \\
\hline Denatonium benzoate & $\mathrm{DB}$ & $9.17 \pm 1.9$ & NL & $5.347 \pm 0.257$ & $3.86 \pm 1.41$ \\
\hline Epigallocatechin gallate & EPI & $0.045 \pm 0.006$ & $0.091 \pm 0.008$ & $0.010 \pm 0.002$ & $0.058 \pm 0.05$ \\
\hline Eucalyptol & EUC & $4.74 \pm 0.7$ & $16.7 \pm 0.721$ & $0.575 \pm 0.068$ & $0.814 \pm 0.64$ \\
\hline Eugenol & EUG & $0.165 \pm 0.112$ & $0.24 \pm 0.03$ & $0.028 \pm 0.002$ & $0.04 \pm 0.001$ \\
\hline Ginger root extract & GRE & $1.54 \pm 0.31$ & $0.79 \pm 0.04$ & $1.75 \pm 0.51$ & $2.8 \pm 0.11$ \\
\hline GMP + inosine monophosphate & GMP + IMP & $83.4 \pm 6.1$ & $58.1 \pm 8.07$ & $56.7 \pm 3.5$ & $59.42 \pm 0.9$ \\
\hline Green tea catechin extract & GTE & NL & NL & $\mathrm{NL}$ & NL \\
\hline Guanosine monophosphate & GMP & $67.6 \pm 17$ & $69.9 \pm 6.3$ & $53.66 \pm 1.36$ & $56.84 \pm 0.95$ \\
\hline Hexahydroisohumulone & HEX & $0.122 \pm 0.03$ & $0.037 \pm 0.007$ & $0.023 \pm 0.001$ & $0.043 \pm 0.002$ \\
\hline Lemongrass oil & LGO & $0.22 \pm 0.012$ & $0.024 \pm 0.015$ & $0.54 \pm 0.04$ & $0.08 \pm 0.01$ \\
\hline Sodium copper chlorophyllin & SCC & $3.4 \pm 3.2$ & $0.137 \pm 0.025$ & $0.127 \pm 0.003$ & $0.283 \pm 0.088$ \\
\hline Sorbose & SORB & NL & NL & $116.78 \pm 7.35$ & $\mathrm{NL}$ \\
\hline Tetrahydroisohumulone & TRA & $0.296 \pm 0.25$ & $0.016 \pm 0.005$ & $0.009 \pm 0.0005$ & $0.031 \pm 0.025$ \\
\hline Thymol & THYM & $0.05 \pm 0.01$ & $0.13 \pm 0.002$ & $0.002 \pm 0.0008$ & $0.002 \pm 0.0001$ \\
\hline Thyme oil & TO & $0.21 \pm 0.03$ & $0.16 \pm 0.01$ & $0.059 \pm 0.001$ & $0.08 \pm 0.003$ \\
\hline Xylitol & XYL & NL & $82.7 \pm 23.5$ & $168.45 \pm 18.51$ & $100.92 \pm 18.71$ \\
\hline$R^{2}$ compared to liver & - & - & 0.934 & 0.991 & 0.990 \\
\hline
\end{tabular}

$\mathrm{NL}$ indicates that no toxicity was observed or that $\mathrm{LC}_{50}$ values could not be calculated at the highest concentrations tested.

chemical property space needed for a balanced quantitative structural activity analysis. In addition, the properties of these compounds were very different, ranging from plant extracts such as GTE, to complex natural aromatic oils like LGO, to specific individual components and chemicals. Many of these natural compounds are complex mixtures obtained from plant extracts, and thus contain multiple potentially active ingredients. For some plant-derived com- pounds, geographical location and time of harvest can effect a mixture's composition. Methods of extract production (water vs. alcoholic reduction) would yield different constituents, making any interstudy comparison difficult unless the same preparation was used., ${ }^{1,59}$

In one specific case in this present study, an extract (EPI) was much more potent than the material from which it was derived (GTE), while for another pair (CLO vs. EUG),
FIG. 5. Radial compass plot comparing 16 compounds (compounds designated as nonlethal were not included) calculated as $\ln$ $\mathrm{LC}_{50}(\mathrm{mg} / \mathrm{ml})$ across all cell lines. $\mathrm{LC}_{50}$ are plotted from the lowest value at the center of the circle outward in In units. Ruler insert depicts approximate comparison between ordinal and logarithmic $\mathrm{LC}_{50}$ values. Compounds are plotted clockwise starting at noon in order of decreasing hepatocyte $\mathrm{LC}_{50}$. Color images available online at www.liebertpub.com/aivt

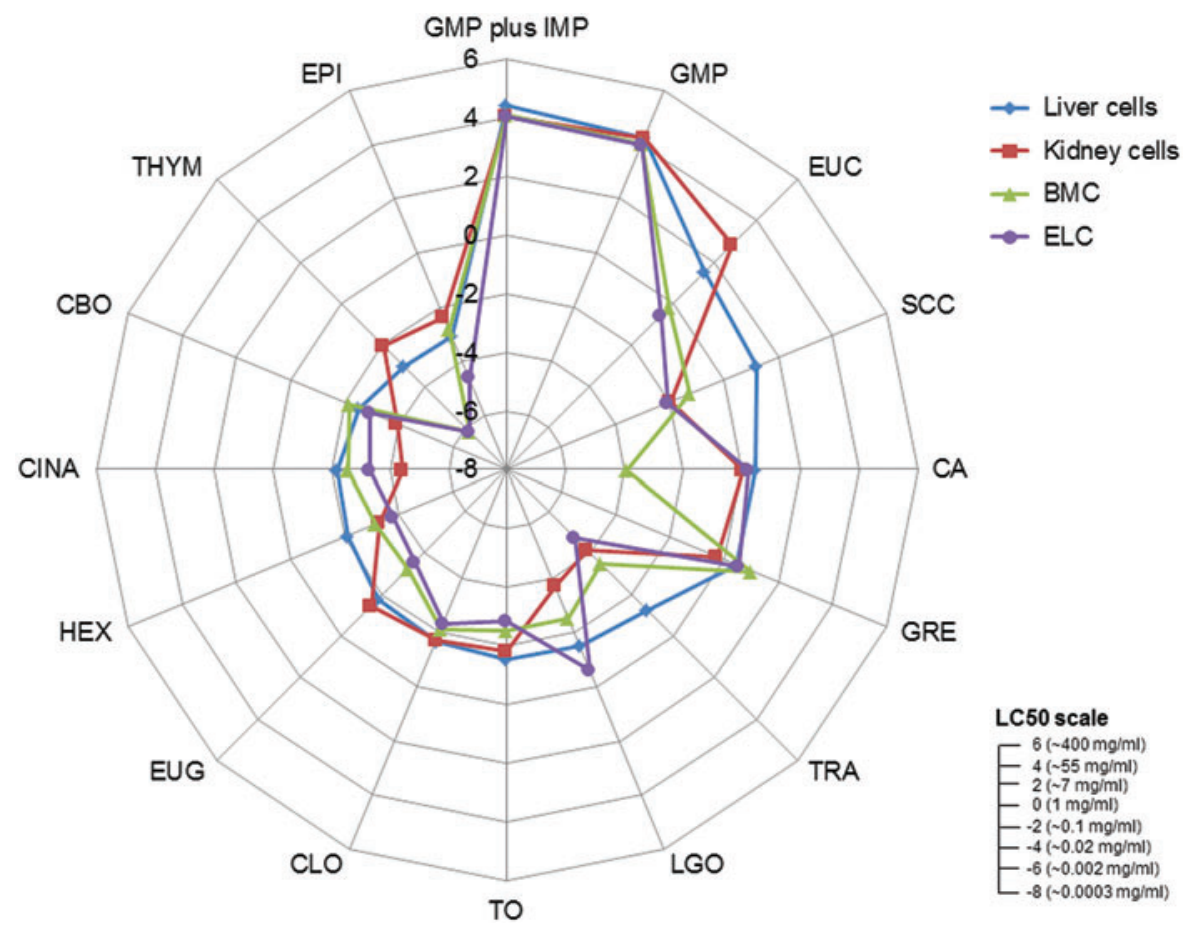




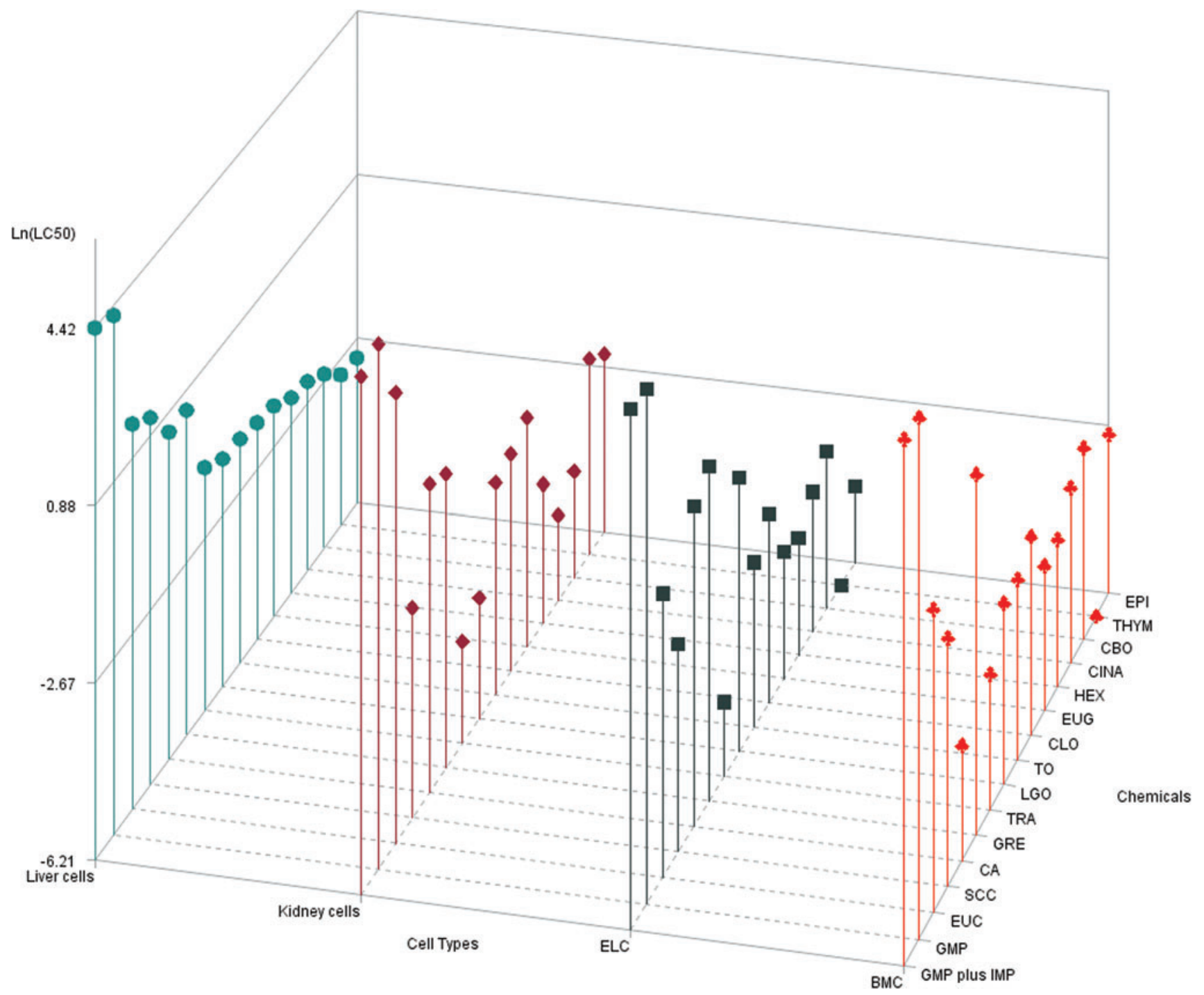

FIG. 6. Comparison of $\ln \mathrm{LC}_{50}(\mathrm{mg} / \mathrm{ml})$ across all 16 compounds (compounds designated as nonlethal were not included) and 4 cell types. Compound $\mathrm{LC}_{50}$ are plotted in decreasing order of hepatotoxicity (left side of graph) to demonstrate different rank orders of toxicity across cell types. Color images available online at www.liebertpub.com/aivt

potencies were similar. As discussed in the Introduction, GTE has been reported to be toxic to dogs, causing lesions in the intestinal mucosa, liver, and kidney after chronic exposure, and more pronounced in the fasted versus the fed state. When these dogs were exposed in the fasted state for 13 weeks, gastrointestinal distress was observed in the absence of severe liver or kidney toxicity. ${ }^{45}$ In our studies, GTE was nonlethal for all cell types, but its component EPI was very toxic across all cell types, especially ELC (Fig. 3b), suggesting that any in vivo effects observed would be related to this component. These findings are consistent with the gastrointestinal toxicity seen in vivo as ELC was the most sensitive cell.

Another finding was the increase in sensitivity of BMSC and ELC compared to renal or hepatic cells to the essential oils EUC, EUG, and THYM. EUC is a cineol compound, whereas both EUG and THYM are phenolic derivatives. It is likely that the lower cytotoxicity observed for these compounds in renal and hepatic cells is because of these cell's increased capacity for biotransformation of these readily metabolized compounds. Our finding of increased ELC toxicity is consistent with essential oil toxicity reported in humans with manifestations including vomiting and diarrhea, consistent with gastrointestinal irritation. ${ }^{60,61}$ Guidelines for use of most essential oils in pets recommend against internal exposure, though all reports are anecdotal.

Hepatocytes were resistant to the water-soluble sodium copper chlorophyllin (Fig. 2f) compared to other cell types, consistent with some observations of gastroenteritis as an early sign of acute copper ingestion. ${ }^{62}$ It is possible that the increased enzymatic capacity of the hepatocyte may offer protection not seen in the other cell types. The BMSC was uniquely sensitive to the CA exposure compared to the other three cell types (Table 1). Because BMSC are young differentiating cells, they may be more sensitive because of lack of developed detoxification systems. The compound $\mathrm{CA}$ might also lower the $\mathrm{pH}$, and so it makes it unsuitable for the BMSC to survive because 
they may not be able to handle acid stress as could more differentiated cells.

The kidney proximal tubule cells were the most sensitive cell type compared to other cells only for LGO exposure (Table 1). As previously reported, gene expression arrays suggested oxidative stress as the primary mechanism in renal cells, in contrast to hepatocytes and BMSC, which showed upregulation of cytochrome P450 enzymes, and ELC showed upregulation of genes involved in heat shock response, beta oxidation, and mitochondrial energy metabolism. ${ }^{6-8}$

The relevance of single-compound cytotoxicity data to effects observed when included in food is also difficult to predict because interactions with other food constituents (e.g., binding and chemical reactions) may occur. ${ }^{63}$ Food served as a protective mechanism in the GTE exposures discussed above. $^{45}$ High-temperature or high-pressure treatments aimed to process and preserve food may decompose some of these chemicals. Compounds in essential oils may volatilize if heat extrusion processes are used in manufacturing. These issues are common to all test systems that do not assess safety of finished products, including in vivo dosing of the pure compound.

The use of alternative toxicity systems such as described herein reduces the use of animals to conduct initial hazard assessments of novel food ingredients. They are useful for probing mechanisms of toxicity in specific cell types when in vivo exposure is known to produce poisoning. In fact, this is consistent with our use of aflatoxin B1 and 4aminophenol as positive controls when we developed these assays in hepatocytes ${ }^{6}$ and in proximal tubule cells, ${ }^{7}$ respectively. There is an ethical concern in conducting a hazard assessment in dogs for products destined for use in dogs. Use of in vitro cell panels begins to assess this concern.

In vitro cytotoxicity assays presented here are useful for many purposes, but also have inherent limitations relative to the ability to extrapolate these results to in vivo responses. When comparative in vitro data are available across multiple species, relative sensitivities can begin to define interspecies comparisons. Such data are also very helpful to design experiments to define (1) mechanisms of compound action, (2) pathways of compound entry into cells, and (3) interactions with other compounds. The primary missing pieces for directly using in vitro data alone for in vivo hazard assessment include (1) absence of knowledge of the delivered target dose to tissues that requires in vivo biodistribution or pharmacokinetic analyses; (2) assessing only parent chemical toxicity, which precludes predicting the toxicological responses if either the parent drug is deactivated to nontoxic metabolites or if the parent compound is bioactivated to toxic intermediates; (3) nonabsorbance of the compound, preventing it from having any systemic effect; and (4) finding toxicological effects only after chronic administration. A consistent finding across all compounds studied was the relative resistance of hepatocytes to cytotoxicity for the compounds evaluateda finding phenomenologically consistent with their function as the cells responsible for xenobiotic detoxification through biotransformation. However, should a specific compound exert its toxicity through metabolic bioactivation, hepatocytes would be most sensitive.

The ELC model does not have these pharmacokinetic limitations because the concentration presented is within the range of that encountered in the gastrointestinal tract in vivo, and direct exposure occurs in both cases. Even in this scenario, intestinal bacterial metabolism of a compound could alter the response. In some cases, in vivo effects would be immunological in origin or mediated from the central nervous system (e.g., emesis through activation of vomiting center) and not amenable to in vitro detection in a single cell type. However, it has been suggested that the primary effects of most xenobiotics are manifested within the gastrointestinal tract and expressed as protective emesis or diarrhea. ${ }^{64}$ We speculate that, if such compounds are acutely toxic to ELC, gastrointestinal distress evidenced by emesis or diarrhea would be observed.

In conclusion, these studies provide a baseline of cytotoxicity responses of 4 canine cell types to a wide variety of 20 different food components that begins to illustrate how such an in vitro panel could be used for hazard assessment. They clearly show the potential strengths of alternative model systems and limitations of such in vitro systems and shed light on interesting activities of some select compounds.

\section{Acknowledgments}

This study was funded by Mars Inc. Global Quality and Food Safety, McLean, VA. Parts of this research were presented at the 54th annual meeting of the National Society of Toxicology in San Diego, CA.

\section{Author Disclosure Statement}

No competing interest exists for any of the authors except B. Jeffery, who is employed by Mars Inc.

\section{References}

1. National Research Council (NRC). Safety of Dietary Supplements for Horses, Dogs and Cats. Washington, DC: National Academy Press; 2009.

2. Rovida C, Asakura S, Daneshian M, et al. Toxicity testing in the 21 st century beyond environmental chemicals. ALTEX 2015:32;171-181.

3. Abdel-Rahman A, Anyangwe N, Carlacci L, et al. The safety and regulation of natural products used as foods and food ingredients. Tox Sci 2011:123;333-348.

4. National Research Council (NRC). Toxicity Testing in the 21st Century: A Vision and a Strategy. Washington, DC: National Academy Press; 2007.

5. Riviere JE. Comparative Pharmacokinetics: Principles, Techniques and Applications. 2nd ed. Ames, IA: WileyBlackwell; 2011.

6. Zhang LW, Koci J, Jeffery B, et al. Safety assessment of potential food ingredients in canine primary hepatocytes. Food Chem Toxicol 2015:78;105-115.

7. Koci J, Jeffery B, Riviere JE, Monteiro-Riviere NA. In vitro safety assessment of food ingredients in canine primary renal proximal tubule cells. Toxicol In Vitro 2015:29; 289-298.

8. Ortega MT, Jeffery B, Riviere JE, Monteiro-Riviere NA. Toxicological effect of pet food ingredients on canine bone-marrow derived mesenchymal stem cells and enterocytes-like cells. J Appl Toxicol 2015; [Epub ahead of print]. doi: 10.1002/jat.3158.

9. Consumer Product Safety Commission United States of America. Final Report Study of Aversive Agents. Technical Report. September 30, 1999. 
10. Hansen SR, Janssen C, Beasley VR. Denatonium benzoate as a deterrent to ingestion of toxic substances: Toxicity and efficacy. Vet Hum Toxicol 1993:35;234-236.

11. Meyerhof W, Batram C, Kuhn C, et al. The molecular receptive ranges of human TAS2R bitter taste receptors. Chem Senses 2010:35;157-170.

12. Miyata M, Kurogi M, Oda M, Saitoh O. Effect of five taste ligands on the release of CCK from an enteroendocrine cell line, STC-1. Biomed Res 2014:35;171-176.

13. Lee RJ, Kofonow JM, Rosen PL, et al. Bitter and sweet taste receptors regulate human upper respiratory innate immunity. J Clin Invest 2014:124;1393-1405.

14. Bhandari AK, Bisht VK, Negi JS, Baunthiyal M. 1, 8Cineole: A predominant component in the essential oil of large cardamom (Amomum subulatum Roxb.). J Med Plants Res 2013:7;1957-1960.

15. Burdock GA. Encyclopedia of Food and Color Additives. Boca Raton, FL: CRC Press; 1997.

16. Machado M, Dinis AM, Santos-Rosa M, et al. Activity of Thymus capitellatus volatile extract, 1,8-cineole and borneol against Leishmania species. Vet Parasitol 2014:200;39-49.

17. Schnitzler P, Schon K, Reichling J. Antiviral activity of Australian tea tree oil and eucalyptus oil against herpes simplex virus in cell culture. Pharmazie 2001:56;343-347.

18. Yang $\mathrm{Z}, \mathrm{Wu} \mathrm{N}, \mathrm{Fu} \mathrm{Y}$, et al. Anti-infectious bronchitis virus (IBV) activity of 1,8-cineole: Effect on nucleocapsid (N) protein. J Biomol Struct Dyn 2010:28;323-330.

19. Santos FA, Rao VSN. Antiinflammatory and antinociceptive effects of 1,8-cineole, a terpenoid oxide present in many plant essential oils. Phytoth Res 2000:14;240-244.

20. Takaishi M, Fujita F, Uchida K, et al. 1,8-cineole, a TRPM8 agonist, is a novel natural antagonist of human TRPA1. Mol Pain 2012:8;1-12.

21. Juergens U, Engelen T, Racke K, et al. Inhibitory activity of 1,8-cineol (eucalyptol) on cytokine production in cultured human lymphocytes and monocytes. Pulmon Pharm Therap 2004:17;281-287.

22. Dorsam B, Wu CF, Efferth T, et al. The eucalyptus oil ingredient 1,8-cineol induces oxidative DNA damage. Arch Toxicol 2014:89;797-805.

23. De Vincenzi M, Silano M, De Vincenzi A, et al. Constituents of aromatic plants: Eucalyptol. Fitoterapia 2002:73; 269-275.

24. Zanoli P, Rivasi M, Zavatti M, et al. New insight in the neuropharmacological activity of Humulus lupulus L. J Ethnopharmacol 2005:102;102-106.

25. Barth R. The Chemistry of the Beer: The Science in the Suds. 1st ed. Ames, IA: Wiley-Blackwell; 2013.

26. Chappel CI, Smith SY, Chagnon M. Subchronic toxicity study of tetrahydroisohumulone and hexahydroisohumulone in the beagle dog. Food Chem Toxicol 1998:36;915-922.

27. Shimura M, Hasumi A, Minato T, et al. Isohumulones modulate blood lipid status through the activation of PPAR alpha. Biochim Biophys Acta 2005:1736;51-60.

28. Yamamoto K, Wang J, Yamamoto S, Tobe H. Suppression of cyclooxygenase-2 gene transcription by humulon of beer hop extract studied with reference to glucocorticoid. FEBS Letts 2000:465;103-106.

29. Bohr G, Klimo K, Zapp J, et al. Cancer chemopreventive potential of humulones and isohumulones (hops $\alpha$-and iso$\alpha$-acids): Induction of $\mathrm{NAD}(\mathrm{P}) \mathrm{H}$ : Quinone reductase as a novel mechanism. Nat Prod Commun 2008:3;1-6.

30. Graham, HN. Green tea composition, consumption, and polyphenol chemistry. Prev Med 1992:21;334-350.
31. Khan N, Afaq F, Saleem M, et al. Targeting multiple signaling pathways by green tea polyphenol (-)-epigallocatechin3-gallate. Cancer Res 2006:66;2500-2505.

32. Crespy V, Williamson G. A review of the health effects of green tea catechins in in vivo animal models. J Nutr 2004:134; 3431S-3440S.

33. Thomson M, Al-Qattan K, Mansour MH, Ali M. Green tea attenuates oxidative stress and downregulates the expression of angiotensin ii AT1 receptor in renal and hepatic tissues of streptozotocin-induced diabetic rats. Evid Based Compl Alt Med Article 2012:ID 409047: 409047.1-10

34. Nasri H, Ahmadi A, Baradaran A, et al. A biochemical study on ameliorative effect of green tea (Camellia sinensis) extract against contrast media induced. J Renal Inj Prev 2014:3;47-49.

35. Yokozawa T, Noh JS, Park CH. Green tea polyphenols for the protection against renal damage caused by oxidative stress. Evid Based Compl Alt Med Article 2012:ID 845917; $1-12$.

36. Inacio JDF, Canto-Cavalheiro MM, Almeida-Amaral EE. In vitro and in vivo effects of EGCG on leishmania amazonesis. J Nat Prod 2013:76;1993-1996.

37. Stoicov C, Saffari R, Houghton J. Green tea inhibits Helicobacter growth in vivo and in vitro. Int J Antimicrob Agents 2009:33;473-478.

38. Bjornsson E, Olsson R. Serious adverse liver reactions associated with herbal weight-loss supplements. J Hepatol 2007: 47;295-302.

39. Bonkovsky HL. Hepatotoxicity associated with supplements containing Chinese green tea (Camellia sinensis). Ann Intern Med 2006:144;68-69.

40. Javaid A, Bonkovsky HL. Hepatotoxicity due to extracts of Chinese green tea (Camellia sinensis): A growing concern. J Hepatol 2006:45;334-336.

41. Jimenez-Saenz M, Martinez-Sanchez MDC. Acute hepatitis associated with the use of green tea infusions. J Hepatol 2006:44;616-617.

42. Molinari M, Watt KDS, Kruszyna T, et al. Acute liver failure induced by green tea extracts: Case report and review of the literature. Liver Transpl 2006:12;1892-1895.

43. Goodin MG, Bray BJ, Rosengren RJ. Sex- and straindependent effect of epigallocatechin gallate (EGCG) and epicatechin gallate (ECG) in the mouse. Food Chem Toxicol 2006:44;1496-1504.

44. Isbrucker RA, Edwards JA, Wolz E, et al. Safety studies on epigalllocatechin gallate (EGCG) preparations. Part 2: Dermal, acute and short-term toxicity studies. Food Chem Toxicol 2006:44;636-650.

45. Kapetanovic IM, Crowell JA, Krishnaraj R, et al. Exposure and toxicity of green tea polyphenols in fasted and nonfasted dogs. Toxicol 2009:260;28-36.

46. Lambert JD, Kennett MJ, Sang S, et al. Hepatotoxicity of high oral dose (-)-epigallocatechin-3-gallate in mice. Food Chem Toxicol 2010:48;409-416.

47. Wu KM, Yao J, Boring D. Green tea extract-induced lethal toxicity in fasted but not in nonfasted dogs. Int $\mathrm{J}$ Toxicol 2011:30;19-20.

48. Galati G, Lin A, Sultan AM, O'Brien PJ. Cellular and in vivo hepatotoxicity caused by green tea phenolic acids and catechins. Free Radical Biol Med 2006:40; 570-580.

49. Code of Federal Regulations. Listing of color additives exempt from certification. Sodium copper chlorophyllin. www.ecfr.gov, 2015; 21CFR73.125. 
50. Osowski A, Pietrzak M, Wieczorek Z, Wieczorek J. Natural compounds in the human diet and their ability to bind mutagens prevents DNA-mutagen intercalation. J Toxicol Environ Health Part A 2010:73;1141-1149.

51. Domijan AM, Gajski G, Novak Jovanović I, et al. In vitro genotoxicity of mycotoxins ochratoxin $\mathrm{A}$ and fumonisin $\mathrm{B}$ (1) could be prevented by sodium copper chlorophyllinImplication to their genotoxic mechanism. Food Chem 2015:170;455-462.

52. El-Ghor AA, Noshy MM, Galal A, Mohamed HR. Normalization of nano-sized $\mathrm{TiO}_{2}$-induced clastogenicity, genotoxicity and mutagenicity by chlorophyllin administration in mice brain, liver, and bone marrow cells. Tox Sci 2014:142; 21-32.

53. Mohamed HRH. Attenuation of nano- $\mathrm{TiO}_{2}$ induced genotoxicity, mutagenicity and apoptosis by chlorophyllin in mice cardiac cells. Int J Sci Res 2014:3;2625-2636.

54. Thiyagarajan P, Kavitha K, Thautam A, et al. Dietary chlorophyllin abrogates TGF $\beta$ signaling to modulate the hallmark capabilities of cancer in an animal model of forestomach carcinogenesis. Tumor Biol 2014:35;6725-6737.

55. Yin LM, Jiang HF, Wang X, et al. Effects of sodium copper chlorophyllin on mesenchymal stem cell function in aplastic anemia mice. Chin J Integr Med 2013:19;360-366.

56. Barbet R, Peiffer I, Hutchins JR, et al. Expression of the 49 human ATP binding cassette (ABC) genes in pluripotent embryonic stem cells and in early- and late-stage multipotent mesenchymal stem cells: Possible role of ABC plasma membrane transporters in maintaining human stem cell pluripotency. Cell Cycle 2012:11;1611-1620.
57. Hinnebusch BF, Siddique A, Henderson JW, et al. 2004 Enterocyte differentiation marker intestinal alkaline phosphatase is a target gene of the gut-enriched Kruppel-like factor. Am J Physiol Gastrointest Liver Physiol 2004: 286;G23-G30.

58. Douard V, Ferraris RP. Regulation of fructose transporter GLUT5 in health and disease. Am J Physiol Endocrinol Metab 2008:259;E227-E237.

59. Dabrowski WM, Sikorski ZE. Toxins in Food. Boca Raton, FL: CRC Press; 2005.

60. Woolf A. Essential oil poisoning. J Toxicol Clin Toxicol 1999:37;721-727.

61. Cameron P, Jelinik G, Everitt I. Textbook of Pediatric Medicine. London: Elsevier; 2006.

62. Gupta RC. Veterinary Toxicology. San Diego, CA: Academic Press; 2012.

63. Scotter MJ, Castle L. Chemical interactions between additives in foodstuffs: A review. Food Addit Contam 2004:21;93-124.

64. Pussa T. Principles of Food Toxicology. 2nd ed. Boca Raton, FL: Taylor and Francis; 2014.

Address correspondence to: Dr. Nancy A. Monteiro-Riviere Department of Anatomy and Physiology Kansas State University 1800 Denison Avenue Manhattan, KS 66506-5802

E-mail: nmonteiro@ksu.edu 